"Learning is not just addition of stimuli to existing cognitive structure of mind.... it is restructuring of existing cognitive structure of mind".

\title{
- Gestalt
}

\section{TEACHERS TRAINING IN MEDICAL COLLEGES - NEED OF THE HOUR}

The medical college and its attached hospitals have dual functions. The attached hospital caters the need of sick people with speciality services usually not available in primary care hospitals. However, a much more important function of the medical college is to produce doctors under strict quality control. This requires great effort by the teachers and the students because in the process of learning there are two variables; teachers, who transmit knowledge and the pupils, who receive it. For effective transmission of knowledge the teacher has not to be only learned but his method of teaching should be immaculate. There comes the role of training of teachers. The process of learning is a continuous one. If the learning either heuristic or cognitive is not updated, they become anachronistic and stale and are unlikely to produce the desired result.

The teachers should have certain essential goals. He must understand the curriculum, state clearly the learning objectives, should recognise the attributes of effective teaching and should effectively plan and use modern educational media (OHPS \& power points) wisely. Their over use is extremely detrimental to the learning process. This is not enough. A teacher has to develop a system of rational assessment of the knowledge perceived by his students.

The teacher student relationship has conceptually changed in the modern era. If the teachers unrealistically assume that a student will place same devotion to them like ancient sage gurus; RISHI VASISTHA, Dhomya etc., then they are looking for a Himalayan disappointment. These ancient Gurus gave knowledge without any fee, rather students were fed for twelve years by Gurus. As now a days the teachers are being paid for their work, the students have now become a consumer. This concept must be clearly appreciated by the teachers.

\author{
Prof. S. M. Mishra \\ MS(Surgery), MS(Ortho), FRCS \\ Editor In Chief
}

